\title{
Refletindo a interface entre trabalho rural e saúde mental dos trabalhadores da citricultura
}

\author{
Ana Cláudia Santos ${ }^{\mathrm{a}}$, Sandra Aiache Menta ${ }^{\mathrm{b}}$ \\ ${ }^{a}$ Universidade Federal de Sergipe - UFS, Lagarto, SE, Brasil.

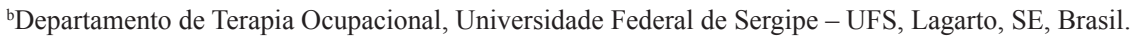

\begin{abstract}
Resumo: Objetivo: Este estudo descritivo apresenta um panorama geral da organização da vigilância em saúde do trabalhador rural, objetivando descrever a estrutura agrária e as condições de trabalho no cultivo da laranja do município de Lagarto-SE, refletindo a relação do trabalho na citricultura com a saúde mental do trabalhador, expresso por meio do abuso de álcool. Método: Trata-se de um estudo exploratório de natureza empírica com abordagem qualitativa, desenvolvida a partir de estudo documental, observação e entrevistas em quatro serviços existentes no município que, de forma direta ou indireta, estariam envolvidos no escopo da atenção integral à saúde do trabalhador. A coleta de dados ocorreu no período de dezembro de 2014 a março de 2015. Resultados: A pesquisa evidenciou a inexistência de um banco de dados com informações sobre os citricultores do município, demonstrando uma fragilidade na efetividade das ações destinadas à saúde do trabalhador. A discussão pontuou a Psicodinâmica do Trabalho trazida por Dejours, refletindo os aspectos da organização do trabalho que afeta o psiquismo dos trabalhadores. Conclusão: Faz-se necessário um olhar quanto ao nexo da saúde mental com o trabalho, pois o processo de adoecer é específico para cada indivíduo, envolvendo o seu cotidiano. Infere-se que o terapeuta ocupacional exerce um papel diferenciado na atenção à saúde do trabalhador, pois a entende a partir da compreensão do mundo do trabalho em suas dimensões históricas, econômicas e sociais. Finaliza com reflexões que visam a despertar um novo olhar para a saúde do trabalhador rural, bem como mudanças em nível local.
\end{abstract}

Palavras-chave: Saúde do Trabalhador, Saúde da População Rural, Saúde Mental, Riscos Ocupacionais, Terapia Ocupacional.

\section{Reflecting the interface between rural work and mental health of citriculture workers}

\begin{abstract}
Objective: This descriptive study provides an overview of the health surveillance of rural workers aiming to describe the agricultural structure and working conditions of citriculture workers in the region of Lagarto/SE and reflect the relationship between citriculture work and the workers mental health, expressed through the alcohol abuse. Method: This is an exploratory study of empirical nature with qualitative approach developed from documental study, observation and interviews in four services that are directly or indirectly involved in the scope of the comprehensive health care of workers. Data collection occurred in the period of December 2014 to March 2015. Results: The study evidenced the lack of a database with information on citrus growers in the municipality, demonstrating a weakness in the effectiveness of actions towards workers' health. The discussion addressed the Psychodynamics of Work by Dejours, reflecting on the work organizational aspects that affect the workers' psyche, which can significantly contribute to the alcohol abuse. Thus, it is necessary to analyze the link between mental health and work, as the process of becoming ill is specific to each individual, taking into account their daily life. Conclusion: From this
\end{abstract}

\footnotetext{
Autor para correspondência: Sandra Aiache Menta, Universidade Federal de Sergipe, Campus Universitário Prof. Antônio Garcia Filho, Av. Governador Marcelo Déda, 330, Bairro São José, CEP 49400-000, Lagarto, SE, Brasil, e-mail: sandramenta@gmail.com

Recebido em Jan. 25, 2016; $1^{\text {a }}$ Revisão em Maio 19, 2016; $2^{\text {a }}$ Revisão em Jul. 6, 2016; $3^{\text {a }}$ Revisão em Ago. 4, 2016 ; Aceito em Ago. 9 , 2016.
} 
we can infer that the occupational therapist plays a differentiated role in the workers' healthcare, as they take into consideration the historical, economic and social dimensions to understand the world of work. The study ends with reflections that aim to encourage a new perspective on the rural workers' health, as well as local changes.

Keywords: Occupational Health, Rural Health, Mental Health, Occupational Risks, Occupational Therapy.

\section{Introdução}

Na contemporaneidade, as relaçóes entre trabalho e saúde do trabalhador, no Brasil, conformam um conjunto complexo, que faz com que coexistam múltiplas situaçóes de trabalho, caracterizadas por diferentes estágios de incorporação tecnológica, diferentes formas de organização e gestão, relaçóes e formas de contrato de trabalho, que refletem sobre o viver, o adoecer e o morrer dos trabalhadores. Essa diversidade de situaçóes de trabalho, padróes de vida e de adoecimento tem se acentuado em decorrência das conjunturas política e econômica. Uma realidade distinta pode ser observada no mundo do trabalho rural, pois estão inseridos em diferentes processos de trabalho: desde a produção familiar, em pequenas propriedades e o extrativismo, até grandes empreendimentos agroindustriais, que se multiplicam em diferentes regiôes do país.

Tradicionalmente, a atividade rural é caracterizada por relaçóes de trabalho à margem das leis brasileiras. A contratação de mão de obra temporária para os períodos da colheita gera o fenômeno dos trabalhadores "boias-frias", que se submetem a precárias condiçôes de trabalho, desde o transporte que utilizam para chegarem ao local de trabalho aos riscos ocupacionais que vivenciam diariamente no ambiente de trabalho (PIETRAFESA, 2011; OLIVEIRA, 2014).

No âmbito rural brasileiro, a citricultura apresenta números expressivos, que traduzem a grande importância econômica e social que esta atividade tem para a economia do país. O Brasil é responsável por quase $30 \%$ de toda a produção mundial, seguido pelos Estados Unidos, que responde por 17,6\% deste total (NEVES et al., 2010).

A citricultura, embora inclua outras frutas cítricas, encontra na laranja o seu principal produto: dos 32 milhóes de toneladas, quase 20 milhóes correspondem à produção somente de laranja (NEVES et al., 2010).

Em Sergipe, a produção de laranja é a segunda maior lavoura permanente do Estado, com área plantada de 50.733 hectares e produção estimada de 822.468 toneladas. Em âmbito nacional, representa somente $3,7 \%$ da produção, porém constitui mais de $40 \%$ de toda a produçáo da Região Nordeste (INSTITUTO..., 2013).

A laranja constitui uma expressiva cultura em termos socioeconômicos, principalmente para as pequenas e médias propriedades rurais da região centro-sul de Sergipe, envolvendo um número considerável de trabalhadores, em razão de ser uma atividade, em sua maior parte, manual, com o uso de expressiva mão de obra de baixa qualificação.

O município de Lagarto representa cerca de $10 \%$ da produçáo e da área plantada de laranja do Estado de Sergipe, e mais de $50 \%$ da população de Lagarto está localizada em domicílios rurais (SERGIPE, 2010).

$\mathrm{Na}$ citricultura, como em várias atividades agrícolas, os venenos agrícolas são usados em larga escala, sendo esta apontada como uma das culturas que mais utilizam pesticida no Brasil, consumindo cerca de 4,0\% do total dos insumos aplicados nos diversos cultivos da agricultura nacional. Esse uso é justificado pelo fato de que os agrotóxicos visam a garantir e/ou melhorar a produtividade por meio de práticas de controle de problemas fitossanitários, conforme o Sindicato Nacional da Indústria de Produtos para Defesa Vegetal (SINDICATO..., 2015).

No entanto, os agrotóxicos estão entre os mais importantes fatores de risco para a saúde dos trabalhadores e para o meio ambiente. A via ocupacional se relaciona à contaminação dos indivíduos que manipulam os pesticidas. Esta contaminação pode ocorrer tanto no processo de formulação (mistura e/ou diluição dos pesticidas para uso) quanto durante o manuseio (pulverização, auxílio na condução das mangueiras dos pulverizadores, descarte de resíduos e embalagens contaminadas, lavagem de equipamentos e destinação de vestimentas contaminadas) e durante a colheita (na qual os indivíduos entram em contato com o produto contaminado) (DYMINSKI, 2006).

Concomitantemente à exposição de agrotóxicos, o trabalho na citricultura expóe o trabalhador a temperaturas elevadas, riscos de acidentes com animais peçonhentos ou com materiais de trabalho, submissão a ritmos acelerados de produção, jornada de trabalho elevada, culminando numa atividade que exige movimentos repetitivos, monótonos e postura inadequada (SILVA et al., 2005; ALVES; GUIMARÃES, 2012).

Nesse cenário em que está inserido o citricultor, o setor agrícola tem sido reconhecido amplamente pelo risco elevado de produzir problemas de saúde relacionados às diversas exposiçóes ocupacionais, sendo apontado, em alguns estudos epidemiológicos, como dos mais perigosos, tornando os trabalhadores 
rurais um grupo dos mais vulneráveis aos efeitos danosos dos agrotóxicos à saúde (FARIA, 2005). No caso do Brasil, esse fato torna-se mais preocupante, pois, desde 2008, o país é o maior consumidor de agrotóxicos no mundo (CARNEIRO et al., 2015).

O Protocolo de Avaliação das Intoxicações Crônicas por Agrotóxicos explica que exposição a uma quantidade elevada de organofosforados (OF) pode desencadear manifestaçóes neuropsiquiátricas, formando um quadro conhecido como chronic organophosphate induced neuropsychiatric disorder ou, simplesmente, COPIND. Esse quadro é observado por meio de sintomas, como sonolência, confusão mental, letargia, ansiedade, labilidade emocional, fadiga, irritabilidade e episódios depressivos, os quais condizem com os níveis alterados da enzima colinesterase sanguínea no indivíduo, podendo perdurar por vários meses após a intoxicação aguda e regredir juntamente com os níveis da colinesterase aos padrōes normais (PARANÁ, 2013).

Alguns estudos brasileiros, considerados pioneiros na temática "saúde mental do trabalhador rural" e que retratam o grande índice de suicídios e a alta ocorrência de problemas mentais, associados à exposição a agrotóxicos, no trabalho rural, sáo trazidos por Faria et al. (1999), numa pesquisa com agricultores da Serra Gaúcha. Entre algumas associaçōes verificadas, a intoxicação por agrotóxicos apresentou uma forte associaçáo com transtornos psiquiátricos menores e apontam estudos que têm mostrado sequelas neuropsicológicas persistentes em pessoas que tiveram intoxicaçóes agudas moderadas e graves por organofosforados.

Uma pesquisa de Falk et al. (1996), realizada em Venâncio Aires-RS, mostra os índices de suicídio na população, que chegaram a ser um dos maiores por cem mil habitantes no Brasil e até no mundo. Os autores apontam que há indícios suficientes para formular a hipótese de que o uso de agrotóxicos (especialmente, os organofosforados) é um dos principais fatores de risco para suicídios.

Araújo, Greggio e Pinheiro (2013) esclarecem que o perfil de adoecimento desses trabalhadores representa um desafio clínico, visto que os distúrbios psíquicos inespecíficos podem ter relação com outras patologias de origem laboral e apresentam uma sintomatologia complexa. Na maioria das vezes, são decorrentes de intoxicação por produtos agrotóxicos, mas podem também estar associados a outros fatores, como: acidentes de trabalho, organização do trabalho e condiçóes precárias que envolvem o trabalho no campo.

A saúde do trabalhador tem sido campo de várias discussóes, por vários profissionais de diferentes áreas. Mas ainda há uma escassez de dados sobre a saúde do trabalhador rural, com abordagens que tragam a interface entre trabalho rural e sofrimento psíquico, e a atenção que tem sido voltada a essa população, com o desenvolvimento de açóes que gerem soluçôes efetivas para essa realidade.

Este estudo descritivo apresenta um panorama geral da organizaçáo da vigilância em saúde do trabalhador rural, objetivando descrever a estrutura agrária e as condiçóes de trabalho no cultivo da laranja do município de Lagarto-SE, e assim refletir a relação do trabalho na citricultura com a saúde mental do trabalhador.

\section{Método}

Trata-se de um estudo exploratório de natureza empírica com abordagem qualitativa, desenvolvido a partir de estudo documental, observação e entrevistas, e centrado na compreensáo dos significados do processo de trabalho dos agricultores de laranja do município de Lagarto-SE. Esta abordagem proporciona uma visão geral da interface entre trabalho rural e saúde mental destes trabalhadores.

Este estudo foi pensando a partir de um projeto de pesquisa iniciado em 2013, pelo Núcleo de Pesquisa e Atenção à Saúde do Trabalhador (NUPAST). Este projeto envolve a avaliação de marcadores biológicos de saúde e de possível intoxicação por organofosforados, a determinação do perfil socioeconômico e o perfil de risco à exposição aos agrotóxicos. $\mathrm{O}$ projeto é intitulado "Análise de indicadores de saúde e marcadores de risco à exposição a agrotóxicos nos trabalhadores das lavouras da laranja nas regióes de maior produção do Estado de Sergipe". Tem aprovação pelo Comitê de Ética em Pesquisa da Universidade Federal de Sergipe, sob o número CAAE 12988313.6.0000.5546, de acordo com a Resolução 466/12 do Conselho Nacional de Saúde (BRASIL, 2013), e é desenvolvido em parceria com Governo do Estado, Governo Municipal e Ministério do Trabalho. É um projeto interdisciplinar, cuja investigação objetiva analisar a saúde do trabalhador da citricultura dos municípios envolvidos.

Por meio das vivências e observaçóes feitas durante as visitas in loco por uma das pesquisadoras do NUPAST, buscou-se verificar a atenção que é dada ao citricultor do município de Lagarto-SE, por parte dos serviços envolvidos com estes.

Assim, foram identificados os serviços existentes no município que, de forma direta ou indireta, mantinham açóes envolvendo o trabalhador rural, com o propósito fundamental de analisar intensivamente esse recorte de unidade social - trabalhadores da citricultura - que, segundo Yin (2002), é uma forma de investigar fenômenos contemporâneos dentro de 
seu contexto de vida real, em situaçóes em que as fronteiras entre o fenômeno e o contexto não estão claramente estabelecidas, e se utilizam múltiplas fontes de evidência.

O município de Lagarto, com população estimada pelo IBGE em 2016 de 103.188 (INSTITUTO..., 2016), é constituído por 119 comunidades rurais, chamados de povoados, nos quais se encontram 6.458 trabalhadores envolvidos na citricultura. Através do NUPAST, os povoados com maior concentração de citricultores foram visitados e pesquisados, trazendo, assim, um maior conhecimento sobre essa realidade social. Entretanto, foi nos serviços envolvidos com o trabalhador rural que se realizou o levantamento de dados dessa pesquisa.

A coleta de dados ocorreu no período de dezembro de 2014 a março de 2015, nos seguintes serviços: Empresa de Desenvolvimento Agropecuário de Sergipe (Emdagro), Centro de Referência em Saúde do Trabalhador (CEREST), Sindicato dos Trabalhadores Rurais e Secretaria Municipal de Saúde (Serviço de Vigilância Epidemiológica).

Utilizou-se de técnicas fundamentais, como a entrevista semiestruturada, com um roteiro previamente elaborado pelas pesquisadoras. Foi realizado contato com as organizaçôes, foram apresentados os objetivos do estudo e esclarecido que o mesmo faz parte do NUPAST e, assim, foram agendados o horário e o local da entrevista com o responsável pelas informaçôes necessárias, expostas pela pesquisadora no momento da coleta. Não houve interferência das pesquisadoras na escolha por parte das organizaçóes quanto à indicaçáo dos entrevistados.

A busca por dados nos locais selecionados, tanto documentais como por meio da entrevista, seguiram parâmetros segundo Glina, Rocha e Batista (2001), Lima (2003, 2006) e Brotto e Dalbello-Araujo (2012), que foram elencados e adaptados para as análises necessárias para o objetivo deste estudo quanto à situação do trabalho. A entrevista orientou-se pelos seguintes tópicos: condiçôes de trabalho, organização do trabalho, relaçóes profissionais, identificação dos riscos de acidentes e agravos à saúde, identificaçáo da atuaçáo sindical e questôes ligadas à garantia de direitos.

Buscou-se elencar quais as informaçôes disponíveis nas bases de dados dos serviços citados, bem como registrar as entrevistas em texto escrito pelo pesquisador, sendo posteriormente analisadas sob a luz do aporte teórico utilizado neste estudo.

Entendendo-se que um dos condicionantes fundamentais para o conhecimento das açóes de políticas integradas de saúde do trabalhador da citricultura vai além dos serviços de saúde, optou-se por ouvir os atores institucionais envolvidos para compreender a complexidade sistêmica das relações em foco, numa perspectiva transdisciplinar, transetorial e intersetorial, reconhecendo que a investigação náo se completa nem se esgota num serviço, numa disciplina ou num grupo profissional.

Para a compreensão da atividade de trabalho, como dados de estrutura agrária, produção agrícola, nível de mecanização e exposiçôes ocupacionais, e para a busca de informações sobre o uso abusivo do álcool e notificaçôes de acidentes de trabalho, para, enfim, levantar os dados necessários para uma análise do caso, utilizou-se o referencial teórico da Dejours (1994), por meio da Psicodinâmica do Trabalho, e, mais especificamente, analisando a saúde mental do trabalhador, através de Lancman (2011). Posteriormente, buscou-se correlacionar os dados encontrados na literatura, através de pesquisa bibliográfica, com os dados encontrados no estudo, embasando, assim, a análise proposta neste trabalho.

\section{Resultados e Discussão}

A Política Nacional de Saúde do Trabalhador preconiza que os Centros de Referência em Saúde do Trabalhador (CEREST) promovam açôes que melhorem as condiçóes de trabalho e a qualidade de vida do trabalhador, por meio da prevenção e da vigilância. Cabe, ao órgão, a promoção da integração e da articulação da rede de serviços de saúde do Sistema Único de Saúde (SUS), na incorporação da Saúde do Trabalhador em sua atuação rotineira, visando a identificar e atender os acidentes e agravos relacionados ao trabalho, em todos os níveis de atenção do SUS, de forma integral e hierarquizada, com base na Lista de Doenças Relacionadas ao Trabalho ou de notificação compulsória (BRASIL, 2009b).

No município pesquisado, o CEREST funciona como polo regional de atenção à saúde do trabalhador. Em visita ao órgáo para coleta dos dados, foi afirmado que não existe um banco de dados com as informaçóes solicitadas, mas, com base nas visitas realizadas no território, se tem conhecimento de como acontece o trabalho do citricultor, a sua organização e os riscos ambientais a que estão expostos, conforme descritos a seguir.

Quanto aos riscos ocupacionais a que os citricultores estáo expostos, foram identificados: 1. Físico: radiação não ionizante (exposição ao sol durante muito tempo diário); 2. Químico: uso de agrotóxico em toda a citricultura da região, podendo levar à intoxicação. 3. Ergonômico: postura inadequada, movimentos 
repetitivos, sobrecarga de peso, ausência de pausa para descanso. 4. Mecânico: acidente com material perfurocortante (enxada, foice) e acidente de trajeto. $\mathrm{O}$ meio de transporte mais utilizado pelos citricultores dessa região é a moto, pois os trabalhadores moram em localidades vizinhas ao local de trabalho.

A forma de trabalho, pelo que é observado, em sua maioria, é informal, sendo remunerados por diária ou por produção. Quando por produção, a necessidade de produzir mais está relacionada ao ganho, influindo diretamente no aumento dos riscos ocupacionais físico e ergonômico.

Quanto à identificação de agravos à saúde, foi relatada a problemática do uso e abuso de álcool pelos trabalhadores. Durante as visitas técnicas no território, pelos técnicos do CEREST, é comum encontrar os trabalhadores no posto de trabalho sob o efeito do álcool. A maioria deles alega que bebem e, em exames clínicos realizados em intervençóes conduzidas pelo CEREST durante o último ano (2014), a maioria dos trabalhadores apresentou alteração no fígado. $\mathrm{O}$ que não se sabe é o que causou essa alteração, se foi o uso do álcool ou do agrotóxico.

Acerca das Notificações de Acidentes de Trabalho, informaram que há pouquíssimas notificações, o que não significa que não aconteçam acidentes, pois, durante as visitas técnicas, os técnicos do CEREST se deparam ou são informados de alguns casos. Salientou-se que esses dados encontram-se no setor da Vigilância Epidemiológica da Secretaria Municipal de Saúde, sendo que as notificaçôes são feitas por agravos e não por classes de trabalhadores. Não há dados que indiquem a quantidade de acidentes de trabalho dos citricultores e, nem no próprio CEREST, há essa informação.

O Sindicato dos Trabalhadores Rurais (STR) foi considerado um campo de pesquisa, por ter este o papel de representar e defender os direitos do trabalhador rural; defender os direitos trabalhistas, sejam estes da previdência rural, da educação e saúde para o campo e da reforma agrária, sejam do fortalecimento da agricultura familiar. O STR atua como um interlocutor dos agricultores familiares e tem se mostrado capaz de pressionar vários órgãos públicos para que estes executem políticas, organizando ações eficazes que beneficiem os agricultores de um modo geral (LOURENÇO, 2009; MALAGODI; BASTOS, 2003).

Apesar do seu relevante papel, não existe um banco de dados sobre os trabalhadores da citricultura do município. Mesmo em nível de informaçôes verbais, foi relatado que, sobre os pontos solicitados, não possuíam dados, visto que o STR trabalha com associados e não com os citricultores em geral, tendo grande demanda de trabalho para questóes que envolvem a previdência social.

Outro órgáo que assume significante funçáo junto aos trabalhadores rurais é a Empresa de Desenvolvimento Agropecuário de Sergipe (EMDAGRO). Esta realiza o serviço de assistência técnica, com açôes julgadas importantes para o desenvolvimento da agropecuária estadual. Executa diferentes projetos, programas e atividades, objetivando a geração de benefícios para a sociedade e, em particular, para os pequenos trabalhadores rurais. Trabalha com base no desenvolvimento de políticas públicas voltadas para a promoção do desenvolvimento rural sustentável.

No município de Lagarto, há duas sedes da instituição. Uma localiza-se no perímetro urbano do município e outra, na zona rural, sendo esta a única sede localizada em zona rural do Estado, por essa região concentrar uma expressiva população de citricultores.

As duas sedes foram consultadas; no entanto, a da área urbana não tinha as informações solicitadas. $\mathrm{Na}$ Emdagro do Povoado Colônia Treze, não há banco de dados disponível, mas as informaçóes coletadas foram bastante detalhadas e os dados solicitados foram contemplados, conforme descrito: a produção agrícola e o nível de mecanização, sendo que, desde o preparo do solo à colheita das frutas, os procedimentos são realizados de forma manual, inclusive a aplicação de herbicidas se dá por pulverizador costal. Apenas em grandes propriedades esse processo é, em sua maior parte, mecanizado tratorizado.

Quanto ao uso de Equipamentos de Proteção Individual (EPIs), o órgão orienta o uso de luva, bota, máscara e macacão; porém, durante as visitas, é comum encontrar os trabalhadores fazendo uso dos herbicidas sem a utilização dos EPIs. É interessante ressaltar que não compete a Emdagro fiscalizar e autuar, mas ao Ministério Federal da Agricultura. O que é observado é que não existe uma consciência por parte dos trabalhadores sobre os reais benefícios dos EPIs e os reais danos que os agrotóxicos podem trazer à saúde.

Em geral, o uso do agrotóxico diminuiu, nessa regiáo, pelo alto custo. Os proprietários têm substituído por Manipueira (líquido extraído da mandioca em casas de farinha, que é desprezado). Ele é rico em ácido cianídrico, é natural, não contamina o meio ambiente e serve para o controle de pragas. Outro produto utilizado é o detergente neutro. Para aplicação destes, a forma de mecanização é a mesma que quando aplicados os herbicidas (manual ou mecanizado). 
Quanto à organização do trabalho, existem quatro classes de trabalhadores, sendo sempre informais: 1. Proprietários da terra; 2 . Trabalhadores do sítio: os que fazem a plantação e a manutenção, e são pagos por diária; aos que fazem a colheita, o pagamento é calculado por produção, por caixa colhida; 3. Carroceiro: realiza a coleta das laranjas, pagos por diária; 4. Carregadores: são contratados pelo caminhão e náo pelo dono da propriedade.

Em relação aos principais riscos ocupacionais e agravos à saúde a que os citricultores estão expostos, foram apontados: exposiçáo a agrotóxico, podendo contrair problemas agudos, quando intoxicados no momento do uso, ou crônicos, através da utilizaçáo contínua do produto, e danos futuros serão contraídos; locomoçáo: principalmente os carregadores são transportados para o local de trabalho em cima de caminhóes, que quando carregados de laranja, os riscos aumentam, pois os citricultores vão em cima da carga, sem proteçáo alguma. Outro meio de transporte utilizado por outros trabalhadores é a moto; uso de álcool: em contato com os proprietários durante as visitas técnicas, estes relatam que, muitas vezes, os trabalhadores colhem e carregam caminhão sob o efeito do álcool. São muitos os casos e, quando graves, eles ficam sem condiçóes de continuar trabalhando, sendo então dispensados do trabalho, aumentando mais ainda a frequência e a quantidade do uso; notificaçóes de acidentes de trabalho: não compete ao órgão essa fiscalização, mas, durante as visitas, é observado ou são informados da existência de alguns acidentes, mas estes não são notificados.

Para verificação das informaçóes sobre acidentes de trabalho e agravos à saúde, foram também coletados os dados da Vigilância Epidemiológica. Esta serve para fornecer subsídios para execução de açôes de controle de doenças e agravos, necessitando, assim, de informaçóes atualizadas sobre a ocorrência dos mesmos. Sua principal forma de obter informaçôes é por meio das notificaçôes de agravos e doenças pelos profissionais de saúde (BRASIL, 2009a).

Foram solicitadas as notificações de acidentes e doenças relacionadas ao trabalho nos anos 2013 e 2014. Como os dados náo sáo por classe de trabalhador, foram verificadas todas as notificações desses dois anos, averiguando a profissão. Dentre as notificaçóes, nenhuma foi de trabalhador rural; a maioria é de profissionais de saúde (enfermeiros e técnicos de enfermagem), ocorridas no atendimento ambulatorial, no hospital.

Com base nos dados coletados, tanto o CEREST quanto a Emdagro afirmaram a ocorrência de agravos e acidentes de trabalho envolvendo o trabalhador rural. No entanto, isso não é confirmado nos dados da Vigilância Epidemiológica, havendo aqui uma incompatibilidade de informações entre o que é percebido durante as vivências das visitas técnicas e o que é registrado nos sistemas de informação.

Ao finalizar a coleta, observou-se que as condiçóes de trabalho encontradas na citricultura da regiáo pesquisada condizem com as condiçóes que envolvem o trabalho rural em outras diferentes atividades rurais. Tais condições já foram foco de alguns poucos estudos encontrados na literatura científica, que mostram a relaçáo do trabalho permeado de condiçóes precárias, de exposiçóes a altos riscos, de desgastes excessivos, como fatores que podem gerar ou desencadear distúrbios psíquicos, inclusive o uso e abuso de álcool, numa relação causal. Além disso, constata-se que o trabalho rural é uma ocupação socialmente desprestigiada, sem alcance das leis trabalhistas e, portanto, visto, nas suas diversas formas, como uma das mais perigosas ocupaçóes em relação à saúde e à segurança do trabalhador (ALESSI; NAVARRO, 1997; ALVES; GUIMARÃES, 2012; BRASIL, 2001; LIMA, 2003; VAISSMAN, 2004; FARIA, 2005; LOPES et al., 2006).

Desses trabalhos de pesquisa, destaca-se o estudo de Lima (2003), realizado numa instituição psiquiátrica, que revelou que algumas categorias profissionais tendem a apresentar distúrbios mentais bastante específicos. Dentre as 23 ocupações classificadas, a mais frequente foi o trabalho rural (19,1\%), com principal diagnóstico identificado de Transtornos Mentais Relacionados ao Uso do Álcool (48,5\%). Segundo o autor, verifica-se, por dados epidemiológicos, uma maior incidência de determinadas patologias, como o uso excessivo de álcool, em determinadas categorias profissionais.

Das pesquisas que vêm sendo realizadas pelo NUPAST, com os citricultores da região de Lagarto, encontram-se disponíveis alguns resultados parciais. Em um dos trabalhos, foram avaliados 303 trabalhadores, tendo sido encontrada uma prevalência de 30,7\% de trabalhadores consumidores de álcool. Os autores ressaltam que não foram encontrados na literatura trabalhos que avaliem o consumo de álcool nesse tipo de população, de trabalhadores rurais, o que dificulta a interpretaçáo sobre a real dimensáo do consumo de álcool nos sujeitos investigados nesse trabalho (ALMEIDA et al., 2013).

No outro estudo (MOREIRA et al., 2013), participaram da pesquisa 60 trabalhadores rurais que estão expostos, direta ou indiretamente, a agrotóxicos organofosforados. Segundo esse estudo, 32,1\% faziam uso de álcool, 20,8\% fumavam e $28 \%$ de trabalhadores apresentavam-se com algum sinal de depressão. Estes resultados evidenciam uma elevada prevalência de tabagismo e consumo de álcool, situações que, em associação com a exposição aos 
organofosforados, podem estar vinculadas à alta taxa de pacientes com hipertensão, doenças respiratórias e sinais de depressão.

Diante dos dados, priorizando-se um dos agravos de saúde, apontado pelos serviços pesquisados como recorrente entre os trabalhadores da citricultura, juntamente com os resultados parciais dos estudos supracitados, além dos achados na literatura pesquisada em outros estudos realizados com o trabalhador rural, cabe a reflexão sobre como o trabalho pode contribuir para o adoecimento mental do trabalhador, evidenciado pelo uso e abuso do álcool. Seria o uso abusivo do álcool uma forma de conviver com as condiçôes precárias de trabalho? É possível ou não estabelecermos um nexo entre certos distúrbios mentais e certas formas de organização do trabalho?

Uma das mais marcantes teorias que explicam as relaçôes entre saúde mental e trabalho é elucidada por Dejours (1994), por meio da Psicodinâmica do Trabalho. Esta enfatiza a centralidade do trabalho na vida dos trabalhadores, examinando os aspectos dessa atividade que podem favorecer a saúde ou a doença. Ao analisar a correlaçáo entre saúde mental e trabalho, o autor acentua o papel da organização do trabalho no que tange aos efeitos negativos ou positivos que aquela possa exercer sobre o funcionamento psíquico e à vida mental do trabalhador. Por meio da Psicodinâmica do Trabalho, tenta-se entender como os trabalhadores submetidos a condições de trabalho desgastantes encontram certo equilíbrio psíquico (DEJOURS; ABDOUCHELI; JAYET, 1994).

Os trabalhadores desenvolvem estratégias defensivas frente aos constrangimentos psíquicos trazidos pelo trabalho, de modo individual ou coletivo. Anormalidade ou equilíbrio se dá em decorrência da dinâmica entre sofrimento e defesa contra este. Quando esse ponto de equilíbrio é perdido e o sofrimento não é mais suportado, surge então o adoecimento. Este

[...] surge quando o trabalhador utilizou todos os recursos intelectuais e psicoafetivos para lidar com as atividades e demandas impostas pela organização e percebe que nada pode fazer para se adaptar e/ou transformar o trabalho (LANCMAN, 2011, p. 273).

Diversos aspectos da situação de trabalho e extra-trabalho podem atuar de forma conjunta no desencadeamento de transtornos mentais, sendo importante atentar para como estes vários aspectos se inter-relacionam, uma vez que entender o nexo entre adoecimento e situaçáo de trabalho não é algo simples, pois tal processo é específico para cada indivíduo, envolvendo sua história de vida e de trabalho (HELOANI; LANCMAN, 2004).

Santos et al. (2007) trazem um estudo da relação entre o trabalho e o alcoolismo, investigando quais são as condiçôes de trabalho que favorecem o desenvolvimento do alcoolismo nos trabalhadores. Com base em Vaissman (2004), os autores refletem a questáo da dependência do álcool não como uma doença de causa orgânica, mas como um fenômeno em que se observam os aspectos biopsicossociais do sujeito. Abordam que os fatores de risco ligados ao trabalho podem ser inerentes à especificidade da ocupação, às condições em que o trabalho é efetuado, ao tipo de agentes estressores e como esses fatores atuam física e psicologicamente no trabalhador. E, por outro lado, existem as características e a vulnerabilidade da personalidade diante do ambiente de trabalho, que favorecerão ou não o uso abusivo.

Os relatos colhidos neste estudo apontam o quanto é comum o uso abusivo do álcool entre os trabalhadores da citricultura da região. Vimos, na literatura pesquisada, o quanto o trabalho faz parte da constituição da identidade individual e das relaçóes sociais. Logo, cabe outra indagaçáo: além da relaçáo do uso e abuso do álcool com a organização do trabalho, geradora de um sofrimento não apenas físico, mas psíquico, seria a necessidade de pertencimento ao grupo outro fator contributivo do uso?

A identidade do indivíduo envolve as características do sujeito que o fazem parecido com os outros sujeitos da mesma classe. Ser um homem é possuir características comuns com o conjunto dos outros homens. Ser um adulto é possuir características comuns com a classe dos adultos. [...] Esta parte da identidade que situa o sujeito no campo social é também significativa da pertinência a uma classe, a um grupo, a um coletivo, a um métier, a uma comunidade (de pertinência) (LANCMAN, 2004, p. 73).

Dejours (1994) corrobora com esse pensar, quando traz que a Psicodinâmica do Trabalho compreende o trabalho como elemento central na construção da saúde e da identidade dos indivíduos, numa influência que vai além do tempo da jornada de trabalho, pois se estende para toda a vida familiar e o tempo do não trabalho.

É a partir do "olhar do outro" que o sujeito se constitui como sujeito, é na relaçáo com o outro que ele se reconhece, num processo de busca de semelhanças e diferenças (LANCMAN, 2011, p. 275). 
Portanto, o trabalho pode ser visto como possuidor de uma função psíquica, enquanto um dos grandes alicerces da constituição do sujeito e da sua rede de significados, sendo constituinte da identidade e da subjetividade do indivíduo, com implicação direta nas diversas formas de inserção e participação social, na constituição de trocas afetivas e econômicas; enfim, é a base da vida cotidiana das pessoas (LANCMAN; GHIRARDI, 2002).

A intenção da discussão reflexiva foi pontuar aspectos da organização do trabalho que contribuem de forma significativa para o uso abusivo do álcool no trabalho, como aliviador das tensóes, como defesa contra os perigos enfrentados e contra tudo que provoca sofrimento. Aliado a isso, é importante refletir acerca da necessidade e da busca de identificar-se com o grupo a que pertence, sentindo-se parte dele, numa relação de influência mútua, em que os aspectos individuais, intrínsecos de cada sujeito, influenciarão o modo de interação.

Como já discorrido, percebe-se que os fatores que envolvem a organização do trabalho da citricultura de Lagarto condizem com as formas encontradas no cenário brasileiro de outras atividades rurais, inclusive a sua relação com a saúde mental. A partir deste trabalho, despertou-se uma reflexão mais pontual, em nível local, em relação à atenção que vem sendo dispensada à saúde do trabalhador rural deste município, visto que foram verificadas a inexistência de banco de dados e a insuficiência de informações encontradas no órgão competente a realizar a vigilância, o que não contribui para a promoção de açóes e a articulação da rede - o CEREST.

A falta de banco de dados culmina num serviço fragilizado e fragmentado, pois o desenvolvimento de ações efetivas direcionadas às reais necessidades da população de citricultores depende de um sistema de informação bem alimentado. Em relação ao CEREST, embora tenha estado presente em toda a pesquisa, notou-se que sua atuaçẫo foi tímida diante de sua atribuição central de oferecer apoio matricial, como retaguarda técnica especializada, a toda a rede SUS. São realizadas algumas açôes embasadas nas abordagens da Saúde Ocupacional e da Medicina do Trabalho, que se distinguem da opçáo do SUS pela saúde do trabalhador, sem articulação com a Saúde Ambiental e com restrição da atuação do órgão junto aos trabalhadores do setor formal (PONTES; RIGOTTO, 2014).

Foi perceptível que os representantes do CEREST demonstraram falta de clareza sobre o papel da instituição, exemplificada pela incipiência de açóes de vigilância em saúde do trabalhador, centrais em suas atribuiçóes. Em parte, isso pode estar relacionado ao receio de entrar em conflito com os gestores municipais, já que essas açôes podem interferir nos interesses econômicos e políticos hegemônicos, e refletir sobre a arrecadação do município e o patrocínio de campanhas eleitorais.

Focalizam-se as atividades nos protocolos de atenção à saúde preconizados pelo Ministério da Saúde que, embora essenciais, por si somente não dão conta da complexidade dos problemas de saúde decorrentes dos processos produtivos na concretude de cada território. Sofrem-se também as implicaçôes da precarizaçáo do trabalho e das dificuldades para atuar em todos os municípios de sua área de abrangência.

Isso traz o desafio de repensar o papel do CEREST e o perfil de seus trabalhadores, de modo a incorporar a abordagem considerada neste artigo. Identificou-se também a necessidade de se reconsiderarem os critérios de seleção e a formação dos trabalhadores que compóem essa instância do Sistema Único de Saúde, ancorando-os no paradigma da Saúde do Trabalhador, com base nos aportes teóricos da Saúde Coletiva.

É imprescindível a construção de uma rede articulada, com dados atualizados que condigam com a realidade, bem como a atuação de equipe multidisciplinar compondo o CEREST, para atuar na atenção à saúde do trabalhador, com um olhar subjetivo do trabalho, uma equipe capacitada para discutir esse adoecimento/sofrimento, de forma a buscar açóes que produzam prevenção de riscos e doenças ocupacionais, além de minimização dos agravos. Uma equipe que seja capaz, enfim, de desenvolver um trabalho permeado por um olhar holístico, numa atençáo que perpasse os mundos objetivo e subjetivo do trabalho.

Para tal, é primordial que as ações em saúde do trabalhador tenham, como foco, as mudanças nos processos de trabalho que contemplem as relaçóes saúde-trabalho-doença em toda sua complexidade, por meio de uma atuação interdisciplinar, intersetorial e multiprofissional. De acordo com Daldon (2012), com o objetivo de melhor contextualização, interpretação e compreensão do mundo do trabalho, a equipe do CEREST deve ser composta por profissionais de várias áreas do conhecimento, tais como: médicos do trabalho e de outras especialidades, assistentes sociais, dentistas, educadores em saúde pública, enfermeiros, engenheiros, fonoaudiólogos, fisioterapeutas, psicólogos, sociólogos, terapeutas ocupacionais, entre outros.

A Terapia Ocupacional vem oferecendo consideráveis contribuiçóes no campo da saúde e do trabalho, entendendo a saúde do trabalhador a partir da compreensão do mundo do trabalho em 
suas dimensóes históricas, econômicas e sociais (WATANABE; NICOLAU, 2001).

O homem é, por natureza, um ser ocupacional, estabelecendo, na maior parte de sua vida, uma relação com o trabalho, que lhe dá identidade e um papel social. Assim, entende-se que uma notável área de atuação da Terapia Ocupacional seja a Saúde do Trabalhador (WATANABE; NICOLAU, 2001).

O terapeuta ocupacional tem, como objeto de atenção na área da Saúde e Trabalho,

[...] a relaçáo estabelecida entre a atividade de trabalho e o trabalhador, expressa na relação consigo próprio (adoecimento), com o seu trabalho (prazer e satisfação no ofício) e com a empresa (cultura e política vigente valorização e reconhecimento) [...],

potencializando as competências pessoais (LANCMAN, 2004, p. 42).

Nos CERESTs, o terapeuta ocupacional está articulado com as demais açóes de saúde, dentro de uma equipe multidisciplinar, podendo executar várias funçóes: intervenção direta em situaçôes de trabalho por meio de açóes de vigilância; atendimentos individuais e/ou em grupos de reflexão com trabalhadores; abordagens preventivas; vigilância das condiçóes e dos postos de trabalho; avaliaçôes funcionais; avaliação dos aspectos psíquicos do trabalho; conscientização sobre os riscos de acidentes ou adoecimentos, dos efeitos do trabalho sobre o indivíduo, e programas de realocação de indivíduos com restriçóes ocupacionais em outras funçóes e postos de trabalho mais adequado a eles, além de desenvolver açóes de educação em saúde e trabalho (LANCMAN, 2004).

Diante disso, infere-se que o terapeuta ocupacional exerce um papel diferenciado na atenção à saúde do trabalhador, pois o trabalho humano sempre foi uma atividade altamente valorizada pela Terapia Ocupacional. Assim como na Psicodinâmica do Trabalho, entende que o trabalho pode ser causa de sofrimento e adoecimento, de aviltamento e de exploração do homem pelo homem, podendo haver formas de trabalho desumanizadoras e nocivas, e outras que podem promover autonomia e saúde (WATANABE; NICOLAU, 2001).

Entende-se que a participação de profissionais de Terapia Ocupacional em pesquisas interdisciplinares na área de saúde do trabalhador é essencial para entender o cotidiano destes trabalhadores e, assim, contribuir efetivamente para a atenção integral de sua saúde.

Pensar a Terapia Ocupacional desenvolvendo açóes junto a trabalhadores com problemas relacionados ao abuso do álcool e outras drogas requer o desenvolvimento de açóes que visem ao alcance de objetivos específicos.

Nogueira e Pereira (2014), ao realizarem um estudo buscando identificar a prática de terapeutas ocupacionais com pessoas em uso problemático de álcool e outras drogas, listaram quais eram os objetivos das atividades propostas. Tanto em atendimento individual como grupal, os profissionais pesquisados buscavam resgatar valores pessoais e sociais; ressignificar as atividades cotidianas, tanto as atividades básicas da vida diária como as atividades instrumentais da vida diária; ampliar a corresponsabilização da família no tratamento, e estimular a expressão de sentimentos e conflitos internos, além de ofertar momentos de lazer e relaxamento, diminuindo a ansiedade e a irritabilidade destas pessoas.

Essas mesmas autoras trazem que a discussão dessa temática ainda é um desafio, visto que verificam escassa produção que discuta sobre a atuação de terapeutas ocupacionais na atenção às pessoas com problemas relacionados ao abuso de álcool e outras drogas (NOGUEIRA; PEREIRA, 2014). Portanto, torna-se mais desafiador ainda discutir a atuação do terapeuta ocupacional na atenção ao trabalhador rural com problemas relacionados ao uso e abuso de álcool e outras drogas.

\section{Conclusão}

Partindo-se do princípio de que a saúde do trabalhador é uma ação transversal e intersetorial, a ser incorporada em todos os níveis de atenção e esferas de gestão do SUS, a participação da terapia ocupacional na composição das equipes de profissionais envolvidos na atenção ao trabalhador contribuiria para aumentar a capacidade de identificação da relação entre o trabalho e o processo saúde-doença que deve ser implantada e/ou implementada desde a atenção primária até o nível terciário, na Rede de Atenção à Saúde, incluindo nas ações de Vigilância em Saúde.

As condiçốes e as exigências do mercado de trabalho na atualidade impactam na saúde mental dos trabalhadores de diferentes formas. Hoje, além de sua relação imediata com o trabalho em si, o que afeta o psiquismo dos trabalhadores são as relações precárias de trabalho - instabilidade no emprego, contratos parciais e/ou temporários, subcontrataçôes etc. Tais relaçóes precárias estão presentes na realidade dos trabalhadores da citricultura, que necessita de um olhar quanto ao nexo da saúde mental com o trabalho, pois o processo de adoecer é específico para cada indivíduo, envolve seu cotidiano. Este trabalho trouxe-nos o conhecimento da organizaçáo 
do trabalho na citricultura, envolvendo um número expressivo de trabalhadores, que vivenciam um trabalho árduo, braçal, repetitivo, que os expóe a toda sorte de riscos ocupacionais e a agravos à saúde, seja por causa externa ou interna, influindo diretamente nos aspectos biopsicossociais do sujeito. É importante ressaltar que, além disso, esses trabalhadores sofrem da exclusão de atenção com o não alcance das açốes desenvolvidas pela rede de atenção à saúde do trabalhador.

Não é nossa pretensão encerrar aqui esse debate reflexivo. Entendemos que seja um assunto que encontra lacunas na literatura e que carece de mudanças em nível local. Portanto, esperamos que este trabalho tenha contribuído para reflexóes, estimulando a um novo olhar para a saúde do trabalhador rural.

\section{Referências}

ALESSI, N. P.; NAVARRO, V. L. Saúde e trabalho rural: o caso dos trabalhadores da cultura canavieira na regiáo de Ribeirão Preto, São Paulo, Brasil. Cadernos de Saúde Pública, Rio de Janeiro, v. 13, n. 2, p. 111-121, 1997.

ALMEIDA, N. O. et al. Análise dos Níveis Séricos de Enzimas Hepáticas e Pancreáticas Associadas ao Uso de Álcool em Trabalhadores Rurais do Município de Lagarto-Se. In: ENCONTRO INTERNACIONAL DE PRODUÇÁO CIENTIFICA - UNICESUMAR, 7., 2013, Maringá. Anais... Maringá: Centro Universitário Cesumar, 2013. Disponível em: <http://www.cesumar.br/prppge/ pesquisa/epcc2013/oit_mostra/trabalhos.php>. Acesso em: 30 set. 2016.

ALVES, R. A.; GUIMARÁES, M. C. De que sofrem os trabalhadores rurais? - Análise dos principais motivos de acidentes e adoecimentos nas atividades rurais. Informe Gepec, Toledo, v. 16, n. 2, p. 39-56, 2012.

ARAÚJO, J. N. G.; GREGGIO, M. R.; PINHEIRO, T. M. M. Agrotóxicos: a semente plantada no corpo e na mente dos trabalhadores rurais. Psicologia em Revista, Belo Horizonte, v. 19, n. 3, p. 389-406, 2013.

BRASIL. Ministério da Saúde. Secretaria de Políticas de Saúde. Departamento de Atenção Básica. Departamento de Açóes Programáticas e Estratégicas. Área Técnica de Saúde do Trabalhador. Saúde do trabalhador. Brasília, 2001.

BRASIL. Ministério da Saúde. Secretária de Vigilância em Saúde. Departamento de Vigilância Epidemiológica. Guia de vigilancia epidemiológica. Brasília, 2009a.

BRASIL. Portaria MS/GM no 2.728, de 11 de novembro de 2009. Dispóe sobre a Rede Nacional de Atenção Integral à saúde do Trabalhador (RENAST) e dá outras providencias. Diário Oficial [da] República Federativa do Brasil, Brasília, DF, 12 nov., 2009b. p. 75-77.

BRASIL. Conselho Nacional de Saúde. Resoluçấo n 466, de 12 de dezembro de 2012. Aprova normas regulamentadoras de pesquisas envolvendo seres humanos. Diário Oficial [da] República Federativa do Brasil, Brasília, 13 jun. 2013.
BROTTO, T. C. A.; DALBELLO-ARAUJO, M. É inerente ao trabalho em saúde o adoecimento de seu trabalhador? Revista Brasileira de Saúde Ocupacional, São Paulo, v. 37, n. 126, p. 290-305, 2012.

CARNEIRO, F. F. et al. (Org.). Dossiê ABRASCO: um alerta sobre os impactos dos agrotóxicos na saúde. Rio de Janeiro: EPSJV; São Paulo: Expressão Popular, 2015.

DALDON, M. T. B. Processo de trabalho dos profissionais de saúde em Vigilância em Saúde do Trabalhador. 2012. 200 f. Dissertação (Mestrado em Ciências da Reabilitaçáo) - Universidade de São Paulo, São Paulo, 2012.

DEJOURS, C. Psicodinâmica do trabalho: contribuições da escola dejouriana à análise da relação prazer, sofrimento trabalho. São Paulo: Atlas, 1994.

DEJOURS, C.; ABDOUCHELI, E.; JAYET, C. Psicodinâmica do trabalho: contribuiçóes da Escola Dejouriana à análise da relação prazer, sofrimento e trabalho. São Paulo: Atlas, 1994.

DYMINSKI, A. S. Contaminação de solos e águas subterrâneas. Curitiba: Universidade Federal do Paraná, 2006. Disponível em: <http://www.cesec.ufpr.br/docente/andrea/TC019_Contaminacao_de_solos.pdf $>$. Acesso em: 28 mar. 2015.

FALK, J. W. et al. Suicídio e doença mental em Venâncio Aires-RS: consequência do uso de agrotóxicos organofosforados. Porto Alegre: INCA, 1996. Relatório preliminar de pesquisa. Disponível em: <http://www2.inca.gov.br/ wps/wcm/connect/observatorio_controle_tabaco/site/ status_politica/fumicultura_e_saude $>$. Acesso em: 30 set. 2016.

FARIA, N. M. X. A Saúde do Trabalhador Rural. 2005. 253 f. Tese (Doutorado em Epidemiologia) - Universidade Federal de Pelotas, Pelotas, 2005.

FARIA, N. M. X. et al. Estudo transversal sobre saúde mental de agricultores da Serra Gaúcha (Brasil). Revista de Saúde Pública, São Paulo, v. 33, n. 4, p. 391-400, 1999.

GLINA, D. M.; ROCHA, L. R.; BATISTA, M. L. Saúde mental e trabalho: uma reflexão sobre o nexo com o trabalho e o diagnóstico, com base na prática. Cadernos de Saúde Pública, Rio de Janeiro, v. 7, n. 3, p. 607-616, 2001.

HELOANI, R.; LANCMAN, S. Psicodinâmica do trabalho: o método clínico de intervenção e investigação. Revista Produção, Florianópolis, v. 14, n. 3, p. 77-86, 2004.

INSTITUTO BRASILEIRO DE GEOGRAFIA E ESTATÍSTICA - IBGE. Levantamento sistemático da produção agricola, Sistema IBGE e recuperação automática - SIDRA. Rio de Janeiro, 2013. Disponível em: <www.ibge. gov.br>. Acesso em: 3 mar. 2015.

INSTITUTO BRASILEIRO DE GEOGRAFIA E ESTATÍSTICA - IBGE. Cidades@: Lagarto. Disponível em: <http://cidades.ibge.gov.br/xtras/perfil.php?lang=\&codmun $=280350 \&$ search=sergipe|lagarto|infograficos:-in formacoes-completas>. Acesso em: 3 jun. 2016.

LANCMAN, S. Saúde, Trabalho e Terapia Ocupacional. São Paulo: Roca, 2004. 
LANCMAN, S. Psicodinâmica do Trabalho. In: CAVALCANTI, A.; GALVÃO, C. Terapia Ocupacional: fundamentação \& prática. Rio de Janeiro: Guanabara Koogan, 2011. p. 271-277.

LANCMAN, S.; GHIRARDI, M. I. G. Pensando novas práticas em Terapia Ocupacional, Saúde e Trabalho. Revista de Terapia Ocupacional da Universidade de Sáo Paulo, São Paulo, v. 13, n. 2, p. 44-50, 2002.

LIMA, M. E. A. A polêmica em torno do nexo causal entre distúrbio mental e trabalho. Psicologia em Revista, Belo Horizonte, v. 10, n. 14, p. 82-91, 2003.

LIMA, M. E. A. Os problemas de saúde na categoria bancária: consideraçóes acerca do estabelecimento do nexo causal. Boletim da Saúde, Porto Alegre, v. 1, n. 20, p. $57-$ 67, 2006.

LOPES, E. S. et al. Avaliação do Esforço Físico Despendido por Trabalhadores nas Atividades de Colheita de Erva mate (Ilexparaguariensis A. St.-Hil.). Floresta, Curitiba, v. 36, n. 1, p. 13-22, 2006.

LOURENÇO, E. A. S. Na trilha da saúde do trabalhador: a experiência de Franca/SP. 2009. 426 f. Tese (Doutorado em Serviço Social) - Universidade Estadual Paulista, Franca, 2009.

MALAGODI, E.; BASTOS, V. S. Sindicato de Trabalhadores Rurais e Agricultura Familiar. GT 21: Sindicatos e Ações Coletivas. In: CONGRESSO BRASILEIRO DE SOCIOLOGIA, 2003, Campinas. Anais... Campinas: Sociedade Brasileira de Sociologia, 2003. Disponível em: <http://www.sbsociologia.com.br/portal/>. Acesso em: 30 set. 2016.

MOREIRA, R. S. et al. Análise do perfil toxicológico e de saúde de trabalhadores rurais do pólo citricultor do município de Lagarto - Sergipe. In: ENCONTRO INTERNACIONAL DE PRODUÇÃO CIENTIFICA - UNICESUMAR, 7., 2013, Maringá. Anais... Maringá: Centro Universitário Cesumar, 2013. Disponível em: <http:// www.cesumar.br/prppge/pesquisa/epcc2013/oit_mostra/ trabalhos.php>. Acesso em: 30 set. 2016.

NEVES, M. F. et al. O Retrato da Citricultura Brasileira. Ribeirão Preto: FEA/USP, 2010.

NOGUEIRA, A. M.; PEREIRA, A. R. Ações de terapeutas ocupacionais na atenção à pessoa com problemas relacionados ao uso de álcool e outras drogas. Cadernos de Terapia Ocupacional da UFSCar, São Carlos, v. 22, n. 2, p. 285-293, 2014.

OLIVEIRA, A. C. Trabalho temporário: bóias-frias na agroindústria canavieira no município de Inhumas-GO.
2014. 133 f. Dissertação (Mestrado em Serviço Social) Pontifícia Universidade Católica de Goiás, Goiás, 2014.

PARANÁ. Secretaria de Estado da Saúde. Superintendência de Vigilância em Saúde. Centro Estadual de Saúde do Trabalhador. Protocolo de Avaliação das Intoxicações Crônicas por Agrotóxicos. Curitiba, 2013.

PIETRAFESA, J. P. A questão trabalhista no mercado sucroalcooleiro no Estado de Goiás. In: JORNADA DE ENSINO, PESQUISA E EXTENSÁO DA UNIEVANGÉLICA, 2., 2011, Anápolis. Anais...Anápolis: NEP-DPCT Editora, 2011. p. 12, 45

PONTES, A. G. V.; RIGOTTO, R. M. Saúde do Trabalhador e Saúde Ambiental: potencialidades e desafios da articulação entre universidade, SUS e movimentos sociais. Revista Brasileira de Saúde Ocupacional, São Paulo, v. 39, n. 130, p. 161-174, 2014.

SANTOS, A. B. et al. Alcoolismo e trabalho: como estão relacionados? In: ENCONTRO DE EXTENSĀO, 2007, João Pessoa. Anais. João Pessoa: UFPB, 2007. Disponível em: <http://www.prac.ufpb.br/anais/IXEnex/extensao/ documentos/anais/6.SAUDE/6PRACPEX01.pdf>. Acesso em: 30 set. 2016.

SERGIPE. Governo do Estado. Secretaria de Estado do Planejamento, Habitação e do Desenvolvimento Urbano. Estatística Sergipe. Aracaju: SEPLAN, 2010. Disponível em: <http://www.seplag.se.gov.br/attachments/article/1385/sergipe_em_dados_2009.pdf>. Acesso em: 28 mar. 2015.

SILVA, J. M. et al. Agrotóxico e trabalho: uma combinação perigosa para a saúde do trabalhador rural. Revista Ciência \& Saúde Coletiva, Rio de Janeiro, v. 10, n. 4, p. 891-903, 2005.

SINDICATO NACIONAL DA INDÚSTRIA DE PRODUTOS PARA DEFESA VEGETAL - SINDIVEG. Balanço 2015: setor de agroquímicos confirma queda de vendas. Sáo Paulo, 2015. Disponível em: <http:// www.sindiveg.org.br/docs/balanco-2015.pdf>.Acesso em: 28 mar. 2015.

VAISSMAN, M. Alcoolismo no trabalho. Rio de Janeiro: Garamond, 2004.

WATANABE, M.; NICOLAU, S. M. A Terapia Ocupacional na interface da saúde e do trabalho. In: DE CARLO, M. M. R. P.; BARTALOTTI, C. C. Terapia Ocupacional no Brasil: fundamentos e perspectivas. São Paulo: Plexus, 2001. p. 155-171.

YIN, R. K. Estudo de caso: planejamento e métodos. Porto Alegre: Bookman, 2002.

\section{Contribuição dos Autores}

Ana Claudia participou de todas as etapas do estudo, incluindo a coleta, análise dos dados e redação do texto. Sandra orientou todas as etapas do estudo, incluindo a coleta, análise dos dados e revisão crítica do texto. Ambas as autoras foram responsáveis pela concepção da pesquisa, revisão do artigo e aprovaram a versão final do texto. 